Journal of Sea Research

February 2019, Volume 144, Pages 156-157

https://doi.org/10.1016/j.seares.2018.12.004

https://archimer.ifremer.fr/doc/00471/58297/

\title{
Flatfish ecology: Advances from the 10th international flatfish symposium
}

\author{
Le Pape Olivier ${ }^{1,}{ }^{*}$, Brind'Amour Anik ${ }^{2}$, Bégout Marie-Laure ${ }^{3}$
}

\footnotetext{
${ }^{1}$ Agrocampus Ouest, UMR 985 ESE Ecologie et santé des écosystèmes, F-35042 Rennes, France

2 Ifremer, EMH, rue de l'île d'Yeu, BP 21105, 44311 Nantes Cedex 03, France

${ }^{3}$ Ifremer, LRH-LR, Place Gaby Coll, 17137 L'Houmeau, France

* Corresponding author : Olivier Le Pape, email address : olivier.le pape@agrocampus-ouest.fr
} 
Since their first edition, the flatfish symposia have provided a platform for all flatfish scientists to share their interest and knowledge in the biology and ecology of this fish group. These symposia are organized every three years, and always stimulate interactions between various scientific disciplines (systematics, morphology, physiology, genetics, ecotoxicology, technology, modeling, population dynamics, ecology, fisheries and aquaculture science, etc.). The last meeting on which this special issue of Journal of Sea Research is based, was entitled "Ten International Flatfish Symposia and $30+$ Years of Advanced Research: Flatfish Ecology in 2017". It was held from $11^{\text {th }}$ to $16^{\text {th }}$ November 2017 in Saint-Malo (France) and aimed to:

- Present emerging research on the biology and ecology of flatfish species worldwide,

- Quantify linkages between flatfishes, atmospheric, oceanographic, and other abiotic and biotic components of the ecosystem,

- Explore management tools for assessing and improving the sustainability of flatfish populations and related human activities (fisheries and aquaculture).

This $10^{\text {th }}$ symposium welcomed 130 attendees from across the globe. In total 5 continents and 19 countries were represented. A selection of 13 papers based on the 8 keynote presentations, 67 talks and 33 posters are published here.

The main insights of the symposium and the related published papers were: 
- Ongoing progress concerning biology, ecology, biotechnology and flatfish aquaculture.

Four related papers were published as summarised here. Van der Veer et al. described life history characteristics of poorly known flatfish species in the Caribbean and did not find the expected patterns of lower growth rate in tropical, temperate and subtropical species. Poiesz et al. analysed the link between food availability and growth of juvenile flounder and plaice in the North Sea. They evidenced that flounder, an epibenthic predator, is less limited by a decrease in prey availability in summer in the North Sea than plaice, an infauna benthic feeder. Joh and Wada (2018) focused on spatio-temporal patterns in timing of spawning and planktonic larval stage duration of yellow striped flounder in Northern Japan and showed the influence of water temperature on both. Tomiyama et al. demonstrated that the optimal temperature for growth of juvenile marbled flounder changes ontogenetically, in accordance with an in situ increase in ambient temperature after settlement in Japanese waters in spring.

- Large improvements in knowledge of flatfish movements and behaviour at different life stages.

New tagging tools and improvements in analysis of natural tracers (otoliths, genetics, stable isotopes, etc) have allowed enhanced multi-tracer research activities. Accordingly, knowledge on spatial connectivity at different life stages has progressed. The accuracy of stocks as management units was also investigated, with metapopulation dynamics of flatfish revealing both small-scale (below stock unit size) spatial structure and exchange between populations, with consequences on effectiveness and appropriateness of management measures. Three related papers were published in this issue as follows. Randon et al. used patterns in growth and asynchrony in cohort densities to evidence spatial structure in the stock of common sole in the Eastern Channel. Sato et al. estimated the genetic structure and demographic connectivity of the marbled flounder in Tokyo Bay, and focused on local segregation at small scales among subpopulations. Lower and 
Soderlung used pop-up archival transmitting tags on the Pacific halibut, and demonstrated connectivity between the Salish Sea and offshore populations in Canada and Alaska.

- Deeper enquiries of anthropogenic pressures impacting flatfish, with a large panel of accounted pressures, i.e., granulate extraction, beach nourishment, wind farms, xenobiotics, eutrophication, direct and indirect effects of fishing, including fishing practice (pulse trawling).

New approaches were presented to infer on local impacts (e.g., exposure to xenobiotics) at population scale. A first set of 3 papers focused on the impacts of global change. Yeung and Yang analysed spatial variation in habitat quality for juvenile flatfish in the south-eastern Bering Sea, and demonstrated that warm-cold environmental phases affect habitat usage, but that the northern drift may not increase productivity. Cheung and Oyinlola proposed a worldwide overview of the vulnerability of flatfish and their fisheries and mariculture to climate change, highlighting regions and species that are expected to be the most impacted. Andrade et al. developed laboratory experiments to analyse the behavioural responses of the speckled sanddab to elevated $\mathrm{CO}_{2}$, and evidenced their relative resilience. Three other papers focused on other anthropogenic pressures. Frisk et al. assessed the drivers of the collapse of the winter flounder throughout the southern New England/mid-Atlantic region. They highlighted the main influence of fishing mortality and the lack of evidence of environmental drivers. Eggleston et al. evidenced the impact of bottom trawling on the diet of 3 of the 4 studied flatfish species in the North Sea. Wilber et al. focused on the impact of wind farms on 7 flatfish species before and during their construction, and then during operation time, without evidencing an attraction effect nor negative consequences.

Steering committee: Janet Duffy-Anderson (NOAA, USA), Josianne Gatt-Stottrup (DTU-Aqua, DK), Elisabeth Fairchild (UNH, USA), Henk van der Veer (NIOZ, NL), Satoshi Katayama (Tohoku U., Japan), 
Tim Loher (IPHC, USA), Richard Nash (IMR, Norway), Jan-Jaap Poos (WUR, NL), Henrique Cabral (Lisbon U., PT), Olivier Le Pape (ACO, France).

Organizing committee: Marie Laure Bégout and Anik Brind'Amour (Ifremer, France), Catherine Le Penven, Amélie Régimbart and Olivier Le Pape (ACO, France), Ingrid de Raad (NIOZ, NL).

Sponsors: NIOZ, ICES, Saint Malo Agglomération, Région Bretagne, Ifremer, Starr Oddi, Thelma Biotel, Vemco-Anhydre, Biologging solutions, Biolog Id, France Filière Pêche, CNPMEM, Cobrénord, Pêcheurs d'Aquitaine, OPPAN. 